\title{
Article
}

\section{The exploration of body-worn video to accelerate the decision-making skills of police officers within an experiential learning environment}

Richards, P., Roberts, D., Britton, M., and Roberts, N.

Available at http://clok.uclan.ac.uk/29139/

Richards, P. ORCID: 0000-0003-4242-981X, Roberts, D., Britton, M., and Roberts, N. (2018) The exploration of body-worn video to accelerate the decision-making skills of police officers within an experiential learning environment. Policing: A Journal of Policy and Practice, 12 (1). pp. 43-49. ISSN $1752-4512$

It is advisable to refer to the publisher's version if you intend to cite from the work. http://dx.doi.org/10.1093/police/pax017

For more information about UCLan's research in this area go to http://www.uclan.ac.uk/researchgroups/ and search for <name of research Group>.

For information about Research generally at UCLan please go to http://www.uclan.ac.uk/research/

All outputs in CLoK are protected by Intellectual Property Rights law, including Copyright law. Copyright, IPR and Moral Rights for the works on this site are retained by the individual authors and/or other copyright owners. Terms and conditions for use of this material are defined in the policies page. 
The exploration of Body-Worn Video to accelerate the decision making skills of Police Officers within an experiential learning environment.

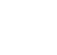

\section{Pam Richards ${ }^{1}$, Professor Debbie Roberts ${ }^{2}$ Inspector Mark Britton ${ }^{3}$ and Nathan Roberts ${ }^{1}$}

\section{Department of Sport and Exercise Science Glyndŵr University, UK}

2. Bangor University, School of Healthcare Sciences, Archimedes Centre, Wrexham, UK.

\section{Isle of Man Police Constabulary, Isle of Man}

Date of $28^{\text {th }}$ October 2016 [resubmitted $11^{\text {th }}$ December $2016 ; 10^{\text {th }}$ February 2017]

Correspondence concerning this article should be addressed to:

Pam Richards

Glyndwr University

Department of Sport and Exercise Science

Plas Coch Campus

Mold Road

Wrexham, LL12 2AW

Phone: +44 (0) 1978365367

Mobile: 07950909229

Email: pam.richards@me.com 
Previous research has highlighted benefits of Body-Worn Video (BWV) to support the work of police officers. The daily demands of policing requires officers to make highly pressurised decisions (with associated rapid action) in unpredictable changing environments.

It is important that new officers learn techniques of decision making in a safe and controlled way, which minimises the risk and harm to all parties whilst at the same time facilitating effective learning. Whilst the benefits of experiential and immersive learning characterised by active participation have long been used in related professional disciplines, the application to police education has been under explored. BWV can be used to identify decision making cues from the environment and nurture pattern recognition, essential to the development of mental models within the officer's decision making process. The paper will therefore explore the application of BWV in the context of experiential immersive learning to accelerate police officers decision making.

Keywords: Body Worn Video cameras, decision making, immersive learning environments, training, reflective practice; 


\section{Introduction}

Since 2012 there has been a surge of interest into the use and application of Body Worn Video (BWV) cameras into the context of modern policing (Lum, Koper, Merola, Scherer \& Reioux 2015). The introduction of such sophisticated technological advancements combined with extensive media interest (Ariel, Farrar \& Sutherland, 2015) has therefore intensified the deliberations surrounding BWV and the role they can play in influencing the public perception of the police and other emergency services (Culhane, Bouman \& Schweitzer 2016; masonadvisory, 2015). According to Custers and Vergow (2015) there is very little robust evidence regarding the effectiveness of using technologies in policing; as very few evaluative studies are being embarked on. However, body worn cameras are associated with "instruments for accountability and an effective way of reducing violence, discrimination or corruption" (Coudert, Butin and Le Métayer 2015: 749). Whilst some authors highlight the potential for body worn cameras to reduce the use of force and limit abuse (Ariel, Farrar and Sutherland 2015), reduce the numbers of stop and search and make subsequent arrests (Ready and Young 2015) and may result in a greater willingness amongst the public to report crime (Ariel 2016); through a range of studies all conducted in the United States of America. Other writers (Grossmith, Owens, Finn, Mann, Davie \& Baika 2015) found that compliance with activating body worn cameras by officers was relatively poor, and was associated with increased likelihood (Grossmith, et al, 2015) of officers to arrest; and seemingly no impact in terms of increased incidence of resisting arrest (Katz et al 2015). Furthermore, Rieken (2013) asserts that officers may lose the discretion that comes as part of interpreting a situation resulting in mechanistic performance. Whilst these studies are important, education and training of officer recruits is not the main aim of this body of work indicating the need for further focused research.

To date the relevance and impact of BWV has not been fully considered and realised within the police training environment. However, experience from members of the research team 
recognises that certain aspects of synthetically created environments have been in existence for some time and have been successfully used in other contexts. For examples HYDRA suites for Senior Investigating Officers training and Simunition simulators are used predominantly with firearms training. Although these environments are valuable they are designed around the creation of simulated environments and they do not have the interactive elements of the artificial intelligent platforms. Research on integrating BWV has only been tentatively explored with two RCT's (Owens et al. 2015; Grossmith et al. 2015) based in the UK, highlighting some potential for continuing professional development when officers have access to BWV footage. Within these two trials the pedagogical underpinning of the mechanism by which such development takes place is sketchy. Currently within police training, the emphasis of the use of BWV has focused on the capture and presentation of evidence in court cases.

While the emphasis of discussions surrounding BWV has focused on increasing the accountability of officers in response to meeting operational demands, other perceived benefits have received less attention. It has been recognised that BWV can provide the additional operational benefits (Grossmith et al. 2015) and facilitate the gathering of evidence through the automated recording of incidences in which officers attend; resulting in a reduction of police use of force (Ariel et al, 2015). In a guidance document Goodall (2007) suggests that in some cases the footage garnered through body worn cameras can facilitate the support of reluctant witnesses in domestic abuse cases. Although a more recent randomised controlled trail indicated increasing proportions of detecting domestic violence but no impact on arrest rates and subsequent sentencing (Owens et al. 2015). Although the complexity of integrating BWV into the strategic and organisational structure of police forces is multifaceted and still very much in its infancy, limited attention has been directed towards the benefit of using BWV in a training environment with the specific aim of helping to accelerate the decision making capabilities of police officers. White (2014) points out that examples of 
body worn cameras in providing opportunities for police training remain largely anecdotal and untested. Although, Goodall (2007) provides some advice outlining the training officers require, regarding technical and practical aspects of using the equipment; he does not go on to consider how body worn camera footage could be used to enhance officer performance; suggesting that there may be a subconscious improvement in officer awareness when they view their own practice (Goodall 2007). The capturing of officers decision making in training situations from the first person's perspective, provides a unique opportunity for officers to engage with experiential learning in a safe and controlled environment. This paper explores the integration of BWV cameras into police training environments to accelerate the development of naturalistic decision making skills in officers. The paper therefore begins by presenting an overview of naturalistic decision making and the challenges faced by officers as they undertake their role in an unpredictable, highly pressurised environment which is continually changing. For the purpose of this paper naturalistic decision making is the term used to outline the investigation of experts in dynamic environments which are uncertain, and are continually changing (Klein, 2008). Such environments are complex and are characterised as containing ill structured problems; shifting, or competing goals; multiple event-feedback loops; time constraints; high stakes; multiple players, organisational norms and goals that must be balanced against the decision-maker's personal choice (Richards et al, 2009). Such characteristics typify the challenging environment of modern day policing. The paper then explores how BWV can be integrated into the training environment of officers, whereby key models and other mechanisms used to support police decision making (College of Policing National Decision Making Model, 2013 and THRIVE) can be embedded into a naturalistic decision-making framework to accelerate the development of decision making skills in officers and new recruits. The paper will then briefly explore how BWV can be combined with other technological advancements (oculus rift, virtual dome environments etc) to create an active experiential immersive learning environment, enabling officers to develop 
associations between cognitive decision making skills and rapid physical actions in a safe and harm free setting. It is envisaged the paper will open discussion as to how policing practitioners and researchers can design safe and controlled training environments which maximise the transfer of learning to real life situations.

\section{Naturalistic Decision Making Skills and the Police Officer}

This commentary paper proposes that the nature of decision making performed by police officers lends itself to the Naturalistic Decision Making paradigm, where decisions are undertaken in highly pressurised, complex and unpredictable circumstances, where time is a key determinant (Klein, 2008). For officers, such environments also include the added complexity of involving multiple individuals. Decision making processes in such a dynamic and continually changing environment requires the integration of perceptual skills and the considerations of situational factors (Richards, Collins \& Mascarhenas, 2016). The design and development of training environments therefore needs to include the development of cue driven perceptual skills relating to the real world context in which the officers may find themselves. Developing the perceptual cues of officers in isolation to the situation could result in the incorrect decision being made when training is transferred to real world settings.

Research from several domains, sport being one, has enhanced our understanding of decision making processes in highly pressurised situations (Starkes \& Ericson, 2003; Williams, 2009; cf. Bar-Eli, Plessner, \& Raab, 2011; Richards, Collins, \& Mascarenhas, 2012). Richards et al (2016) proposed two interconnected models within one framework which addresses the development of decision making skills in highly dynamic and pressurised environments. Although originally designed for the development of decision making skills in elite sport the framework is being explored in the context of developing decision making skills in police recruits on the Isle of Man. Model 1 in the empirically tested framework (see Richards et al, 
2016 for review) outlines how important information relevant to real world contexts can be pedagogically layered. This first model integrates the individual's knowledge, situational factors and the context of the setting in which the individual is making the decision. The second part of the framework illustrates how integrating reflective (slow deliberation) training environments within scenario based settings (Richards et al, 2012) can result in the facilitation of accelerated decision making skills, through the process of layering the information. There has been a considerable body of research illustrating that slow deliberate learning which occurs in an experiential scenario based video environment can accelerate the decision making skills in highly pressurised naturalistic field settings (Richards et al, 2009; 2012; Merola \& Richards, 2010; Bates \& Richards, 2011 and Richards, Penrose \& Turner, 2015). The slow deliberate video based learning environment empowers individuals to construct specific mental models in the context of their own performance. Within the mechanism advocated here, the beginner or less experienced recruit can learn from and have access to the mental model of the more experienced officer as they both watch footage of a situation together.

Through the observation of video recorded from BWV officers (individual officers or a specialist team of officers) it is proposed that officers can engage in deliberate, structured discussions. Such engagement empowers the officers (individually or collectively as a team) to identify key features and important aspects of the clip, which results in the formulation of individual or shared mental models (Richards et al, 2012; Richards et al, 2016). Westbrook (2006) highlighted that mental models are only valuable to the individuals who construct them; indicating that everyone is required to construct their own mental model. Focused discussion between individuals can therefore make mental models accessible resulting in more effective engagement when similar situations arise in the future (cf. Mascarenhas, Collins, Mortimer, \& Morris, 2005). The connection between the empowered slow deliberate learning environment and the applied real world context (where decision are made in real life 
situations) is evident in the model through an interacting pair of feed-forward and feedback mechanisms (Richards et al, 2016). Feedback discussion features aspects of what was completed well; whereas feedforward discussions focus on what needs to be incorporated into future actions if a similar situation arises.

The authors of this paper therefore proposed that footage captured from BWV could be integrated within the decision framework proposed by Richards et al (2016) enabling training officers to apply specific police decision making models (THRIVE and NDM ) to enhance the decision making skills of officers when on patrol.

\section{Developing a video based learning environment to facilitate Decision Making Skills in} Police Officers

Effective teaching should enable students to assimilate new knowledge into existing cognitive structures (Andrews \& Roberts, 2003). Simulated or immersive learning environments enable students to do so through active participation. Such simulated immersive learning environments are being used in a range of associated professional disciplines such as medical and nurse education to enable students to observe, rehearse and practise in an approximation of the real world. Through immersion in scenario based learning encounters, students are enabled to draw on all of their senses to facilitate decision-making in real time (Roberts \& Roberts, 2014). Typically simulation features active participation by the learner followed by structured de-briefing with an expert or skilled facilitator where meaning and sense making can be achieved.

The process of sense making facilitates the officer moving beyond the identification and comprehension of environmental cues which are being discussed and the trainee officer is encouraged to frame or comprehend the cue in relation to the situation. Sense making therefore would facilitate the trainee officer establishing connections and associations 
between environmental cues. Such an empowered, slow deliberate process of sense making results in the development of the individual's own mental model or internalised plan (Richards et al, 2012; 2012), which in turn can be used to inform and shape actions in future situations (Bates \& Richards, 2011).

Whilst active participation in a learning environment is important; there is a growing recognition that individuals can also learn vicariously through the experiences of others; being able to listen to experts as they discuss a new topic, enables students to learn through such active discussion (Roberts, 2010). (Although it is recognised that this is often dependent on the skills of the teacher in facilitating learning.) Utilising BWV footage captured either through everyday work or through judiciously selected and recreated simulated scenarios ensures that the stimulus for learning is rooted in the real world of policing, where the knowledge on which professionals draw is broad, deep and multi-faceted; moreover, the problems which professionals face are not straightforward, rather they are complex and messy (Schon, 1987). We postulate that as the experienced officer and the beginner watch the BWV footage together they can focus their discussion on the environmental and embodied cues (data points) that the expert experienced officer has identified to frame (or contextualise) the situation. As the discussion unfolds, the beginner is given access to the mental model of the experienced officer as their craft knowledge is shared. This craft knowledge can then be used to inform future action of the novice officer, when they are confronted with a similar real world situation.

It is proposed that the integration of BWV footage into learning environments combined with engagement in structured conversations (empowered slow deliberate learning) between expert or experienced officer and less experienced, or those at the beginning of their police careers could accelerate decision making skills. We believe there is a potential that real world police decision making can be accelerated and enhanced through such approaches. Furthermore, the initial work being undertaken in this field of inquiry warrants closer attention. 
232

In conclusion, BWV footage could be integrated into simulated training environments which are specifically designed to accelerate the decision making skills of police officers. The integration of structured discussions between expert or experienced officers and those at the beginning of their careers facilitates a slow deliberate empowered learning environment that creates the opportunity for officers to explore highly pressurised situations but in a controlled and risk free setting. The structuring of the video based learning environment would empower the officers to develop effective mental models of decision making which relate to a specific policing context (e.g. drunk and disorderly). Integrating BWV into a simulated and/or immersive learning environment facilitates officers being able to identify and prioritise environmental cues and contextualise (frame) this visual information in context of the real life situations which they may find themselves.

The challenge for policing practitioners and researchers is therefore to integrate emerging technology into specifically designed and constructed training environments which are free from harm, maximise and accelerate decision making skills in officers but which are economically viable. There is potential to use a range of emerging technology in conjunction with BWV footage to create such a learning context. Eye tracking technology would generate an understanding of the search patterns or ability to 'read the scene' of expert officers when they are attending an incident (scenarios created in a training context). Such information could be useful in providing a framework for understanding how expert officers think. The use of BWV could also be integrated with single user digital technology platforms such as Oculus Rift (a head mounted display, that exposes its wearer to a bespoke interactive 360-degree immersive environment, deployed using virtual reality) providing the benefits of learning in a harm free environment; and which enable the learner to repeatedly encounter training situations in order to refine their response. Finally, the construction of immersive learning environments, such as 3D virtual domes (an enclosed 360 degree interactive environment 
where a range of environments can be projected using conventional game development techniques to produce 3D digital content) (Roberts \& Roberts, 2014) could be used to facilitate the development and collaboration of team decision making skills between officers, as multiple individuals can engage in scenario based training collectively in risk free training context.

It is hoped that this paper may open discussion as to how BWV can be integrated with video based /immersive learning environments; whereby empowering officers to engage in slow deliberate learning processes can accelerate the development and acceleration of decision making skills which are transferable to real life situations.

\section{References}

Andrews, M. and Roberts, D. (2003). Supporting Student Nurses Learning in and Through Clinical Practice: The Role of the Clinical Guide. Nurse Education Today. 23: 471-481.

Ariel, B. (2016). Increasing Cooperation With the Police Using Body Worn Cameras. Police Quarterly, 19(3): 326-362.

Ariel, B., Farrar, W. and Sutherland, A. (2015). The Effects of Police Body-Worn Cameras on use of Force and Citizens' Complaints Against the Police: A Randomized Controlled Trial. Journal of Qualitative Criminology, 31 (3): 509 - 535.

Bar-Eli, M., Plessner, H., \& Raab, M. (2011). Judgment decision making and success in sport. West Sussex, UK: John Wiley \& Sons, Ltd.

Bates, B., \& Richards, P. (2011). Developing Team Decision Making Capabilities in a Professional Football Team. Paper presented at British Association of Sport and Exercise Sciences National Student Conference, Chester. 
College of Policing (2013). National Decision Model; available at https://www.app.college.police.uk/app-content/national-decision-model/the-nationaldeicison-model/ [Accessed1September 2016].

Coudert, F., Butin, D. and Le Métayer, D. (2015). Body-worn cameras for police accountability: Opportunities and risks. Computer Law \& Security Review. 31: 749-762.

Culhane, S.E., Bouman J.H. and Schweitzer K. (2016). Public perception of the justifiability of police shootings: The role of body cameras in a pre-and post-Ferguson experiment. Police Quarterly 19 (3): 251 - 274.

Custers, B. and Vergouw, B. (2015). Promising policing technologies: Experiences, obstacles and police needs regarding law enforcement technologies. Computer law \& security review 31: 518-526.

Goodall, M. (2007). Guidance for the Police use of body-worn video devices. Police and Crime Standards Directorate. Home Office. ISBN: 978-1-84726-344-5.

Grossmith, L., Owens, C., Finn, W., Mann., Davies. and Baika, L. (2015). Police, Camera, Evidence: London's cluster randomised controlled trial of Body Worn Video; available at http://whatworks.college.police.uk/Research/Documents/Police_Camera_Evidence.pdf [Accessed 7 February 2017].

Katz, CM., Kurtenbach, M., Choate, D.E. and White, M.D. (2015). Phoenix, Arizona, Smart Policing Initiative. Evaluating the Impact of Police Officer Body-Worn Cameras; available at http://www.smartpolicinginitiative.com/sites/all/files/Phoenix\%20SPI\%20Spotlight\%20F INAL.pdf [Accessed 28 November 2016].

Klein, G. (2008). Naturalistic Decision Making. Human Factors, 50(3): 456-460. 
Lum, C., Koper, C.S., Merola, L.M., Scherer, A. and Reioux, A. (2015). Existing and Ongoing Body Worn Camera Research: Knowledge gaps and opportunities; available at http://cebcp.org/wp-content/technology/BodyWornCameraResearch.pdf [Accessed 4 February 2017].

Mascarenhas, D. R. D., Collins, D., Mortimer, P., and Morris, R. L. (2005). Training accurate and coherent decision-making in rugby union referees. The Sport Psychologist, 19: 131147.

Masonadvisory. (2015). Police, Camera, Action! Getting the Best from Body-Worn Video. White paper; available at https://www.bwvsg.com [Accessed 19 October 2016].

Merola, T. and Richards, P. (2010). Developing Decision Making Skill in Youth Footballers. British Association of Sport and Exercise Sciences National Student Conference, Aberystwyth.

Owens, C., Mann, D. and Mckenna, R. (2015). The Essex Body Worn Video Trial. The impact of Body Worn Video on criminal justice outcomes of domestic abuse incidents. College of Policing, UK; available at http://whatworks.college.police.uk/Research/Documents/BWV_Report.pdf [Accessed 7 February 2017].

Ready, J.T., and Young, J.T.N. (2015). The impact of on-officer video cameras on policecitizen contacts: findings from a controlled experiment in Mesa, AZ. Journal of Experimental Criminology, 11: 445-458. DOI 10.1007/s11292-015-9237-8

Richards, P., Mascarenhas, D. R. D. and Collins, D. (2009). Implementing Reflective Practice Approaches with Elite Team Athletes: Parameters of Success. International Journal of Reflective Practice, 10(3): 353-363. 
Richards, P., Collins, D. and Mascarenhas, D. R.D. (2012). Developing Rapid High-Pressure Team Decision-Making Skills. The integration of slow deliberate reflective learning within the competitive performance environment: A case study of elite netball. International Journal of Reflective Practice, 1-18. DOI: 10.1080/14623943.2012.670111

Richards, P., Collins, D. \& Mascarenhas, D. R.D. (2016). Developing Team Decision Making: A Holistic Framework Integrating both On-Field and Off-Field Pedagogical Coaching Processes. Sports Coach Review, 1-19. doi.org/10.1080/21640629.2016.1200819

Richards, P., Penrose, S. and Turner, M. (2015). Developing Team Decision Making Capabilities in elite football Youth Academy Players. MMU CRiC International Coaching Conference, Crewe, UK.

Rieken J. (2013). Making situated police practice visible: a study examining professional activity for the maintenance of social control with video data from the field. $\mathrm{PhD}$ thesis, The London School of Economics and Political Science (LSE).

Roberts D. (2010). Vicarious Learning: A Review of the Literature. Nurse Education in Practice, 10 (1): 13-16. doi:10.1016/j.nepr.2009.01.017

Roberts, D. and Roberts, N.J. (2014). Maximising Sensory Learning Through Immersive Education. Journal of Nursing Education and Practice, 4 (10): 74-79.

Schön, D. (1987). Educating the Reflective Practitioner. Jossey-Bass, San Francisco.

Starkes, J. L. and Ericson, K. A. (2003). Expert Performance in Sports: Advance Research on Sport Expertise. Champaign, IL: Human Kinetics.

Westbrook, L. (2006). Mental Models: A Theoretical Overview and Preliminary Study. Journal of Information Services, 32, 563-579. Office of Community Oriented Policing Services. 
White, M.D. (2014). Police Officer Body-Worn Cameras: Assessing the Evidence.

351 Washington, DC.

352

Williams, A. M. (2009). Perceiving the Intentions of Others: How Do Skilled Performers Make Anticipation Judgments? In M. Raab, J. G. Johnson, \& H. R. Heekeren (Eds.), Progress in Brain Research, New York: Elsevier, pp. 73-83.

355 